\title{
How Digital Life Changes our Personal Economy - A Market Analysis
}

\author{
Gianluca Zaffiro \\ gianluca.zaffiro@telecomitalia.it | Telecom Italia S.p.A. Via G. Reiss Romoli 274 - 10148 Torino, Italy \\ Ioannis Mourgis \\ yiannis.mourgis@gmail.com | GrowthRocks, London, United Kingdom, N2 0PE
}

\begin{abstract}
Digital life", intended as the consequence of being connected to any device, anytime, anywhere and the "sharing economy" phenomenon are impacting and changing both business and individual activities. Mass collaboration is emerging through multiple new tools for people and companies, generating a clear advantage in terms of effectiveness, creativeness and competitiveness. In this paper, we analyze how individuals are engaging the evolution of personal (peer) economics to identify the best cases of the most remarkable crowd-based start-ups. Moreover a new model is described on how big companies could leverage the crowd, with an open innovation approach.
\end{abstract}

Keywords. Digital Technology; Access Economy; Mass Collaboration; Sharing Economy.

Cite paper as: Zaffiro, G., Mourgis, I. (2018). How Digital Life Changes our Personal Economy - A Market Analysis, Journal of Innovation Management, www.open-jim.org, 6(1), 13-31. http://hdl.handle.net/10216/111571 


\section{Introduction}

In 2013 researchers at NASA started wondering if there should be a better way to find life out of our planetary system: at that time, in fact, NASA employees were facing the problem of lack of time for such researches. As a solution, they decided to use the power of the crowd. They created a project called "Planet Hunters", open to everyone, to enable observations through the Kepler telescope. Remarkably, more than ten planets, suitable for life, have been discovered so far. This is an example how the power of crowdsourcing is one of the most effective tools that can be used to solve real problems and to create wealth. It brings better qualitative results and optimize processes, acting as a new collective human intelligence - not artificial at all.

This approach could be at the basis of the sharing economy (or collaborative consumption), which can be defined as a phenomenon that builds on a class of economic arrangements and technological ICT-related developments, which enables distribution, sharing and reuse among participants of excess capacity of products or services. As such, the sharing economy model goes beyond individual ownerships (Hamari et al., 2015). Like crowdsourcing, it is another direct consequence of Digital life.

Next sections elaborate how the sharing economy is emerging among individuals and how it could become a model for businesses by leveraging the crowd. Specifically, Section 2 provides an overview of the expected sharing economy market impacts. The drivers and barriers to crowdsourcing are reported in Section 3. Section 4 describes some examples of presently emerging activities, and a speculation on future ones is described in Section 5. Finally, Section 6 summarizes the main conclusions, recommendations and offers an outlook.

\section{Market}

The collaborative economy is considered as the third web-based innovation wave (Rick, 2013). Venture capitalists are showing great attention to this sector, investing a total of $\$ 172$ billion over a 12 year span on several start-ups that are addressing peer-to-peer $(\mathrm{P} 2 \mathrm{P})$ marketplace solutions (Regner, 2014).

PwC claims that the emerging sharing economy is going to reach the same revenue value of the traditional competitive economic sectors (PriceWaterhouseCoopers, 2014), growing from $5 \%$ of market share in 2013 to $50 \%$ in 2025 and $\$ 335$ billion in value.

According to (Deloitte, 2015), Facebook stimulates $\$ 227$ billion of external value and 2.7 million jobs, through three broad effects: a) marketing tools, b) App environment, c) connectivity catalyst. These effects occur by third party operations in the Facebook ecosystem and exclude the operations of the company itself: the value of connected crowd is always higher that the market value, because of the side effects of interconnectivity (i.e., the so-called "network effect").

\section{Drivers and Barriers to Crowdsourcing}

As a new technological and societal trend, this phenomenon has not been consistently regulated yet, especially with reference to labor, local laws, taxation and intellectual property rights. 
Nevertheless, strong technological and environmental driving forces are triggering it.

\subsection{Political Drivers}

Political decisions can be slow and have a negative impact on the sharing economy grow, nevertheless many local policy makers are acting to sustain it. For example, policy makers in Amsterdam, London, Paris, New York and San Francisco made agreements with AirBnB.com to provide a safer framework in short term house rental. These kinds of agreements for the sharing economy companies are not easy neither cheap. In fact, big money is spent for political activism and lobbying to protect the right of sharing. In 2014 Uber.com spent nearly $\$ 500.000$ over a five-month period to lobby with state legislators in Sacramento and AirBnB spent $\$ 400,000$ (Van den Dolder, 2014). The Washington Post looked at local lobbyist registration records and found that Uber hired at least 161 lobbyists in at least 50 USA cities and states over a 2 year time (Kosoff, 2014).

Modern consumer society is characterized by political apathy, in contrast to a healthy democracy that was always based on sharing (Parsons, 2014). As soon as citizens understand that the sharing economy has the potential to democratize the local wealth to all society, then also politicians will bring the change as an effect, despite the traditional sectors disruptions.

\subsection{Economic Drivers}

The main economic benefits for the rapid spread of the sharing economy are based on the most effective use of resources which increase the productivity, providing more profits to the owners (Fehrenbacher, 2010). Resources that were unused before, such as excess or idle inventory, can be now monetized.

Users have gained the alternative to pay per use or per task and to increase financial flexibility. Also, they have access over unique ownership or personalized experiences that they could not afford or get before, thus gaining extra value.

Usually there is no taxation on revenues as long there is no legal framework, causing negative effects on society and on business owners. Many efforts are going on on this issue. For example, in 2017 AirBnB has spontaneously introduced in its terms of service a paragraph on "taxes", where it makes hosts responsible for any kind of taxes and where it declares its willing to facilitate direct collection and remittance of occupancy taxes in some jurisdictions (AirBnB, 2018).

\subsection{Social Drivers}

\section{1) Trustworthiness}

The trust in individuals in the digital age is declining, as a change of consumer's behavior (Badger, 2015). Younger generations feel more and more difficult to trust through digital streams. Only $19 \%$ of millennials trust others, compared to $40 \%$ of baby boomers (Pew Research Center, 2014). Anyway, uncertainty has been tackled up to one point, adopting crossed verifications done by the users themselves and by interfacing to other networks. Also, the psychological and emotional 
rewards of a successful interaction produce strong bonds and interpersonal trust (Parigi and Cook, 2015) and generates a virtuous circle.

The paradox of the American sharing economy is that the USA have the less willingness to share (Richter, 2014) and at the same time the higher adoption percentage of the sharing economy (Elks, 2014). In other words: "Uber, AirBnB and Kickstarter made Americans trust, share and help each other" (Tanz, 2014).

2) Employment

Digitization is disrupting all traditional jobs. Many strikes have been made against platforms like Uber and they are showing the problem created to the traditional employment market (Herbst, 2014). But the reality is that the sharing economy is replacing work with microworking and democratizing the spread of the sector's profits to the microworker crowd. Sharing economy workers can generally expect to earn a higher hourly wage through freelance assignments than through traditional channels (Sundararajan, 2016), even if this does not imply a higher annual income compared to the traditional equivalent. Uber drivers benefit significantly from real-time flexibility, earning more than twice the surplus they would in less flexible arrangements (Chen et al., 2017).

A massive adoption of the sharing economy can completely change the way we live and work (Howard, 2015). Some economists believe that we will overpass from traditional B2B (businessto-business) or B2C (business-to-consumer) models to an almost inclusive H2H (human-tohuman) one; meaning that the crowd will finally offer the crowd as a solution in every possible sector.

3) Overpopulation

More than 8 billion people will be on earth by 2030 and most of them will be living in big cities (United Nations, 2015). In this scenario crowdsharing is necessary to ensure resources for more citizens. Also, the use of social networks and platforms generates a resurgence of residential communities.

\subsection{Technological Drivers}

The main technological drivers are basically P2P technologies that enable social connectedness key factor for social profiles and reputations tracking - and the evolution of personal and mobile devices.

\subsection{Environmental Drivers}

Scientists warn that recycling is just not enough to tackle environmental problems, which should be faced holistically at their very core and not only looking at their effects. For such a reason, sharing has a great potential in the future (Childs, 2013), as it fights the problem proactively at the real core of consumption.

Potentially a sharing economy approach for cars could reduce $20 \%$ of the total USA energy related $\mathrm{CO}_{2}$ emissions produced by personal vehicles. In big cities like Berlin or New York, respectively $46 \%$ and $56 \%$ of the population manage without their own vehicle, while the rest 
of urban residents who still own vehicles don't use them very often - for example in Munich for just 45 minutes a day (Hüetlin, 2013). The University of California claimed that each shared car replaces 9 to 13 owned ones (Buczynski, 2011; Pick, 2012).

According to Fast Company, home sharing is $66 \%$ more effective than hotel accommodation (Scorpio, 2012). It is still early to measure a holistic environmental impact, because even though AirBnB travelers can travel cheaper, maybe they travel more (Schor, 2016). Moreover, even if more house capacity is used, still hotel construction keeps increasing (Gunther, 2014).

\subsection{Legal Drivers}

There are many legal pitfalls of crowdsourcing (Wolfson and Lease, 2011). Legal systems are changing slower than the spread of new technologies, such as crowdsourcing, producing many legal gaps. Local legal differences are making impossible to have a global legal policy for the sharing economy platforms. For these reasons, $72 \%$ of AirBnB users violated state zoning regulations according to New York State Attorney (Straifeld, 2014).

Most practices in the sharing economy are innovative and oscillate between the border of personal and commercial activities, therefore difficult to regulate them. Regulators should look at practices that are regarded as substitutes to similar commercial goods and services. At this level regulation should address compulsory contracts between parties, compensation, minimum skill requirements and liability (Ranchordas, 2015).

Besides local barriers, there are two more structural legal issues: employment and intellectual property rights.

Ultimately it is not clear if any crowd-worker would be classified as an employee under the Fair Labor Standards Act (FLSA) applied in the USA. This uncertainty, however, means that potential employers must be aware of the possibility of regulation (Gellman, 2015).

Companies face several intellectual property and confidentiality risks when conducting a crowdsourced project (Lieberstein et al., 2012):

- submissions that contain infringing or unauthorized material;

- crowdsourced submitter lacks assets or resources to indemnify the company;

- increased contractual obligations and insurance coverage;

- consumer data in crowdsourcing projects can raise issues pertaining to the consumer's right of privacy.

A better evaluation of intellectual property risks should include determination of contributors, interactions with the company, crowdsourcing submissions confidentiality, requirements on proof of originality or general novelty and the expenditure to the crowd (Lieberstein and Tucker, 2012).

A strong intellectual property right protection encourages innovation, and, on the other hand, a weak one leads to innovations because it favors their diffusion (Blind, 2012). A good way to reach the two goals simultaneously may be to have in mind this ambivalence also in the crowdsourcing context. 


\subsection{Enablers}

The enablers for the sharing economy can be categorized in 1) methods to create the service; 2) pricing and business model; 3) access types or the mechanisms to share the resources.

The methods reported in this section were identified by (Botsman and Rogers, 2010) and have been integrated with others that can be observed in the activities mentioned in Section 5, such as gamification and open innovation. Pricing models have been derived by observing the business models of the initiatives, as described in Section 4 and 5.

The alternative business models in Table 1 are common in the sharing economy and used by most of the companies. The use of one model does not exclude the others. Pricing in the sharing economy is much more innovative and creative than in the traditional markets.

Access is critical in the sharing economy platforms. In 2001 the futurist J. Rifkin described this phenomenon as "The Age of Access" (Rifkin, 2001). The World Economic Forum identified as types of access the following: renting, lending, subscribing, reselling, swapping and donating (World Economic Forum, 2013).

When designing a sharing economy service, some tools can be considered to develop a platform with a go-to-market philosophy and to handle trustworthiness. Solutions like Sharetribe.com, MyTurn.com and Near-Me.com can generate a complete sharing marketplace platform in minutes, using SaaS (Software as a Service) technologies, helping entrepreneurs to test in advance the market value and letting them pay as their ideas grow.

Table 1. The sharing economy methods and pricing / business models

\begin{tabular}{lll}
\hline Methods & & \\
\hline Name & Description & Example \\
\hline Micro-tasking & $\begin{array}{l}\text { a series of small tasks which together comprise a large } \\
\text { unified project, done by many people over the Internet }\end{array}$ & $\begin{array}{l}\text { TaskRabbit, } \\
\text { MTurk }\end{array}$ \\
\hline Crowdification & $\begin{array}{l}\text { utilizing the crowd for every task (from new product defi- } \\
\text { nition, to development, to funding, to support and more) }\end{array}$ & $\begin{array}{l}\text { BlaBlaCar, } \\
\text { Kickstarter }\end{array}$ \\
\hline Incentivation & $\begin{array}{l}\text { the alignment of different user motivations, for instance } \\
\text { giving a prize to best solutions in a contest }\end{array}$ & GoPillar \\
\hline Open Innovation & $\begin{array}{l}\text { use of both inflows and outflows of knowledge to improve } \\
\text { internal innovation }\end{array}$ & AT\&T TIP \\
\hline Gamification & $\begin{array}{l}\text { application of game-design elements and principles in non- } \\
\text { game contexts }\end{array}$ & CellSlider.net \\
\hline Pricing / Business Model & Example \\
\hline Name & Description & AirBnB \\
\hline Pay per use & mainly for properties \& experience & Lending Club, \\
\hline $\begin{array}{l}\text { Auction } \\
\text { mechanism }\end{array}$ & dynamic demand-supply matching & \\
\hline
\end{tabular}




\begin{tabular}{lll} 
Winner Contest & pay only for the best solution & GoPillar \\
\hline $\begin{array}{l}\text { Sharing of future } \\
\text { profits }\end{array}$ & equity or skill sharing & MakeitApp.eu \\
\hline $\begin{array}{l}\text { Pre-pay per } \\
\text { solution/ product }\end{array}$ & reward crowd-funding & Kickstarter \\
\hline
\end{tabular}

According to the Edelman Trust Barometer published annually (Edelman, 2018), trust in media outlets, businesses, government institutions, and non-governmental organizations (NGOs) has declined significantly in the past decade. Trustworthiness among users is key in the online world, and particularly to the sharing economy, as discussed in Section 3: solutions like Deemly.co were introduced to offer white-label mechanisms that manage and publish information about the user reputation.

\subsection{The "digital life" shakes business and individual activities}

The technological evolution towards digitization and widespread connectivity allows to simplify the access to resources and offers the tools for managing them. This is the key factor for enabling the sharing economy and crowdsourcing, as explained in the previous paragraphs. The methods with which to implement a sharing economy service leverage the "fractioning" of the resources - a fraction of work activity, a fraction of use of a product or a service - and are implemented through a digital platform, on which a reward model is then engaged; trust between the parties is essential to success.

The instantiation of a sharing economy service has consequences both for individuals, companies, and society. This fact calls for intervention policies to guarantee fair treatment for all parties and avoid creating gray areas. Regulations and laws should secure the rights of all actors, whether they are individuals, new businesses or traditional businesses that come into conflict with new ones.

The spread of the sharing economy makes the use of resources more efficient, which brings benefits in terms of environmental sustainability, although the democratization of access could, on the contrary, increase the negative externalities. The growth of the global population makes the sharing economy and mass collaboration instruments to overcome the difficulties of meeting their needs, just as the "fluidification" introduced in the world of work may bring advantages (increase in opportunities) and disadvantages (inequality). Finally, the introduction in the companies of open tools to increase innovation leads to issues of intellectual property that must be addressed.

Since sharing economy services are based on ICT access tools, the privacy and data protection aspects of their users should be carefully addressed by service providers. In the first half of 2018, two significant regulations are coming to force in Europe to address these topics: the Directive on payment services in the internal market (PSD2, 2015) and the General Data Protection Regulation (GDPR, 2016). These regulations will impact the sharing economy: PSD2 by catalyzing new third-party services, and GDPR by empowering consumers with more stringent consent requirements and more accountability and transparency in customer data use, building a more trustworthy experience. 


\section{Presently Impacted Sectors}

Today we are witnessing the success of the sharing economy in several market sectors, including: commerce, tourism, transportation, professional services, financial and education. The levels of success can be measured, for example, by observing the number of startups working in each sector, the value of venture capital fund received, the number of involved users and the social impact.

\subsection{Commerce Sector}

Amazon and eBay follow the P2P model as general marketplaces:

"When eBay started in 1995, it was not a slam dunk that people would send money across the country to nearly anonymous sellers, and these sellers would reciprocate by sending back items as advertised." (Einav et al., 2015, p.9).

These kinds of transactions could never not work without a mechanism that enables trustworthiness.

Nowadays, there are online platforms where people can share almost any kind of personal product, like clothing (RentTheRunway.com), accessories (Stylelend.com), jewelry (Rocksbox.com), and professional equipment (Munirent.co). Digitization and 3D printing technologies are offering the crowd new ways to produce and share commercial products (Shapeways.com, Thingiverse.com).

\subsection{Tourism Sector}

In tourism AirBnB has become the most popular sharing economy platform for short-term accommodation. The Boston University estimated that the impact on hotel revenues was roughly 8-10\% in urbanized areas such as Austin, Texas (Zervas et al., 2015). This caused a measured result of price reductions that potentially benefits all consumers.

Several entrepreneurs are trying to export the AirBnB model to smaller and more homogeneous markets: boat tourism (Boatbound.com), caravan tourism (Yescapa.fr), working office space (LiquidSpace.com, PivotDesk.com), event venues (EventUp.com), pet hotels (DogVacay.com, Rover.com), travel agencies (Evaneos.com, Vayable.com), tour guides (GetYourGuide.com).

\subsection{Transportation Sector}

Transportation has been crowdsourced in many ways. Carpooling consists of two methods:

- real-time ride sharing based on mobile devices - e.g.: Uber;

- on-demand ride sharing - e.g.: BlaBlaCar.

Car-sharing for short period rentals can be based on P2P technologies (e.g. Turo.com, Getaround.com, Drivy.com) or on city-based centralized systems (e.g. Zipcar.com, Car2Go.com), where the cars belong to the rental company and not to community of peers. 
Uber started in 2009 and received about $\$ 20$ billion of funding so far. It operates in 53 countries and more than 600 cities worldwide, despite competition and many legal actions against it. Uber became the most popular and controversial sharing economy paradigm, giving birth to the term "uberization".

Another well-known example in this sector is BlaBlaCar, which connects drivers with empty seats to paying passengers and offsets distance travel costs. BlaBlaCar is not based on maximizing overall profits, but on creating economies of scale and being more environmental friendly. Despite this philosophy, BlaBlaCar is making the expansion in the USA harder than in the European market (Korosec, 2015), where it already operates in 17 countries. The pricing model starts as a freemium service and then switches to a freemium-premium model (which includes some insurance benefits) after reaching the country critical mass.

An established car maker like General Motors is looking at the sharing economy to innovate its business model: General Motors announced a pilot program of a car sharing service, called Maven. The car owners will use the Maven app to rent out their vehicles when they aren't using them (Welch, 2018).

Other impacted transportation sectors are: airplane sharing (Coavmi, Wingly), logistics (Postmates, Deliv.co, Glovo), park sharing (Sparky, JustPark.com, SpotHero, Luxe).

\subsection{Professional Services}

Professional services are offered by P2P platforms either as freelancing or micro-working generalpurpose services or in specific sector marketplaces.

Best cases for freelance services are Elance.com, Freelancer.com, PeoplePerHour.com, Coworks.com. The most representative cases for microwork services, which are providing simpler tasks compared to freelance ones, are Mechanical Turk by Amazon, TaskRabbit.com, Fiverr.com, SuperTasker.com, Thumbtack.com.

Professional services in specific fields count architecture (Arcbazar.com), interior design (GoPillar.com), design (99designs.com), animation (ArtCorgi.com), advertising (Zooppa.com), software development (Toptal.com), consultant analysis (Experfy.com), house cleaning (Helpling.com, Handy.com), house services Servicewhale.com), beauty (StyleSeat.com, Vaniday), journalism (Ebyline.com).

\subsection{Financial Sector}

Crowd-based solutions are impacting massively the financial sector, with the introduction of new type of services such as crowdfunding, crowd-banking, equity crowdfunding and other P2P financial services.

Crowdfunding platforms raised $\$ 2.7$ billion and successfully funded more than 1 million campaigns only in 2012. According to Massolution, global crowdfunding volumes have raised more than 2-fold year-to-year to reach in 2015 a volume of $\$ 34.4$ billion (Massolution, 2015). The top platforms are Kickstarter, Indiegogo, Crowdfunder, RocketHub and FundRazr. Globally the USA are the country with the highest participation, having funded over 6.000 projects so far 
(The Crowd Datacenter, 2014).

Equity crowdfunding faced several legal problems, but some countries managed to remove most of the barriers allowing this sector to grow (Tordera, 2013). Some of the best platforms are AngelList, CircleUp, OurCrowd, Companisto, Crowdcube.

Crowd credit, loan and deposit marketplaces are using P2P technology to lower the cost of the traditional banking system. They allow their peers to invest in each other in a financially and socially beneficial way. Participants could be also small and medium-sized businesses. Loans usually have lower rates, flexible terms, no early repayment fees. Some examples include: Lending Club, Prosper, Funding Circle, Zopa, RateSetter, Upstart, Earnest, Auxmoney and LoanNow.

Other examples reside in the insurance sector with startups like Friendsurance that created the first P2P insurance network.

\subsection{Education Sector}

The social impact of the sharing economy in education is quite impressive. Only Duolingo.com, a freemium language-learning platform, has 18 million active monthly users (Amazon Web Services, 2016). Originally language courses were completely free, with no ads displayed as the content itself was completely made by the users and translated text of learners could be sold to customers like Wikipedia or CNN. In 2017 Duolingo decided to move to a new business model based on ads, certification tests, and in-app purchases (Ramirez, 2017). Didactic learning goals can be achieved rapidly thanks to friend's interaction, skill tree environment (with user progress) and data-driven approach to lesson planning. An average of 34 hours of Duolingo equates to a full university semester of language education (Vesselino and Greco, 2012).

Academic courses from high class universities are available from online platforms like EdX, Coursera.com, OpenLearning.com. Tutorials about specific topics could be found from Lynda.com, Udemy, Skillshare.com. Finally, classmates' notes can be found from CourseHero.com.

\subsection{How "digital life" impacts our personal economy}

Previous paragraphs described how an individual can benefit from being connected online via a personal device such as a computer or a smartphone: the purchase or rental of an asset can be done without physically moving, virtually extending the number of choices and empowering to access to the cheapest or fastest to get product or service.

The same advantages apply to hospitality: users can be immediately informed by the reviews of people who have already used the accommodation, and cut costs by dealing directly with those who offer hospitality.

The sharing economy has also considerably impacted the transport sector: the greatest advantages for the individual are in the ease with which you can find a vehicle, use it when you need it and where you need it, without having to own the vehicle or take time to sign a rental contract. Similar advantages are obtained when one may wish offering professional skills or, vice versa, finding someone who can help in a specific activity, or finance an idea without going to a financial institution (e.g., by reaching out to people who believe in that idea, and finally train in a subject 
accessing from wherever it is convenient.

All these examples have in common the fact of making it simpler, easier, faster, often cheaper than before.

Businesses wishing to leverage the sharing economy, in case of lack or insufficiency of indications in the legal framework, should be prepared to take autonomous initiatives - such as AirBnB did with the management of the taxation of hospitality (see paragraph 3.2).

The application of the sharing economy is not limited to the field of business, but it intersects civil society in the broad sense. Therefore, intervention policies will be necessary to guarantee fairness of rights and opportunities for all the actors, whether they are the individuals who use the service, the new business actors or the traditional businesses that come into conflict with the new ones - for example, Uber versus taxi unions.

\section{Future Impacted Sectors}

In the coming years, as technology evolves, the sharing economy will have major impacts also in the energy, telecommunications and healthcare sectors, which are currently controlled by big corporations. Besides, innovation will be boosted by the crowd-based open innovation approach, progressively being adopted by large companies.

\subsection{Energy Sector}

The crowd is already involved in energy marketplaces, renewable energy financing and smart grids.

P2P energy sharing marketplaces empower people and corporations to share and donate energy to their friends, family or organization they care about. Early examples are: Gridmates.com, OpenUtility.com and Vandebron.nl.

Renewable energy financing is changing the way people generate and pay for their electricity and it supports local energy producers, having an impact on solar clean energy projects. The best example is joinMosaic.com.

Finally, smart grid providers like ParetoEnergy.com are offering a core smart grid infrastructure combined with software solutions. Battery energy storage systems, that are core to the smart grid infrastructure, could also be more economically sustainable when operated under a sharing scenario (Lombardi and Schwabe, 2017).

\subsection{Telecommunication Sector}

The "uberization" of the telecommunication sector is happening via over-the-top services and network virtualization.

Crowdsourced Wi-Fi Internet service providers allow Wi-Fi customers to share their connections with others in return for free access to other hotspots around the world. A globally successful example is Fon.com, running a hotspot network of 13 million nodes worldwide: each customer 
shares some of its network service and in return receives free of charge what would otherwise be a paid-for service. Fon.com has partnered with several operators such as British Telecom, Vodafone, SFR France, SoftBank, KPN Netherlands, Deutsche Telekom, Telstra.

A reward mechanism of sharing data plan with strangers is what Karma, a $4 \mathrm{G}$ provider founded in New York city in 2012, promotes. Karma transforms hotspots into an open Wi-Fi network: when a new user joins the network of an owner of Karma, the latter gets 100 MByte of free data credited to her account. The company calls this model "social telecom". Other examples are NetZero, FreedomPop and Ting.

OpenGarden.com is the first "off-the-grid" messaging App, that works even without Internet connection or cellular phone coverage and already connects 3 million users worldwide. It uses a software-based mobile broadband network made of P2P connections between devices, while it leverages the density of them to create an OTT network. Another example was Endaga, a locally-owned, small-scale, independent cellular network run by and for rural communities, acquired by Facebook in 2015. Similarly, Rhizomatica runs a wireless mesh that allows smartphones to communicate, even in the case of catastrophic failure of cellular networks. These early examples can suggest a trend towards $\mathrm{P} 2 \mathrm{P}$ mobile connections, especially for the digital divide affected communities.

\subsection{Healthcare Sector}

In 2011 Susannah Fox, associate director of the Pew Research Center's Internet Project, said that

"peer-to-peer healthcare is a way for people to do what they have always done-lend a hand, lend an ear, lend advice - but at Internet speed and at Internet scale" (Fox, 2011, p.1).

Bio-medical research could improve by engaging the crowd to participate with simple and gamified tasks, like the MalariaSpot.org online app that uses a gamified process of diagnosing malaria by the crowd. Or CellSlider.net, a project set up in 2012 that shared images from tumors with the general public, enabling them to score tumor markers independently through an Internet-based interface, involving nearly 100,000 people (Candido dos Reis et al., 2015).

Hospital equipment can be shared: Cohealo.com provides an asset sharing mobilization and analytics platform for the healthcare industry equipment and Floow2.com offers a general B2B asset sharing which includes equipment, services and personnel.

\subsection{Open Innovation Becomes Crowd-based}

Open innovation, as opposite to internal R\&D activities, is

the use of purposive inflows and outflows of knowledge to accelerate internal innovation, and expand the markets for external use of innovation, respectively" (Chesbrough, 2011, p.1).

There are many models to generate corporate value in an open innovation approach. Many companies are adopting a practice called product platforming, which is based on the use of open 
APIs (Application Program Interface) or SDK (Software Development Kit) of other company products. Other methods are leveraging idea competitions, customer immersion, collaborative product design, innovation networks, joint labs with Universities and start-ups engagement.

Open innovation in the corporate context is based, like the sharing economy, on online cooperative platforms and "softwarization". The latter is transforming industrial systems from closed ones (hardware-centric) into open ones (software-managed). This trend creates the following benefits: first, easily sharing tasks among internal or external experts that are not physically co-present; second, creating a complex solution by integrating components that are developed in an ecosystem of partners.

The adoption of these models requires a company to strongly leverage on its innovation resources: the "crowds" inside and around the organization. It is common practice to include customers, employees or other industry and market partners, into several open innovation models (Stähler, 2010). An example of crowd involvement in innovation is the AT\&T TIP initiative (AT\&T, 2014).

\subsection{How "digital life" will impact corporate economy}

In the previous paragraphs how the digitization and the fact that software and computing capabilities can be found everywhere is acting as a disintermediation factor and distributing production capacities, once concentrated in a single actor, was described. In the energy context, local production will be able to enter the redistribution circle of energy; in the context of telecommunications, the "softwarization" will lower the technological barrier to offer/consume any digital services (e.g., from connectivity to processing, from storage to any sort of programmable application). The healthcare sector will take advantage of digitization, especially through the sharing of resources and exploiting data and crowd intelligence.

Finally, the entire innovation process will gain new energy from the "liquidity" introduced by digitalization and "softwarization", making it possible for an ecosystem of actors, either individuals or company partners, to contribute to open innovation projects, by engaging on a framework designed to integrate the best solutions.

The adoption of open innovation tools in companies must be supported by reasoning on the underlying intellectual property aspects (and risks), or vice versa those who participate in these models as contributors will have to verify if and which rules are followed. Appropriate terms and conditions could be used to balance and mitigate the risks associated with soliciting solutions from a crowd (De Beer et al., 2017).

\section{Conclusions}

The core mechanism of sharing economy relies on the "fluidification" of work activities and any access to products and/or services, implemented through a digital platform. This mechanism allows individuals and businesses to access new operational or creative resources, increasing opportunities to meet a need and the potential for business success.

The sharing economy offers companies numerous opportunities to adapt their business models to 
capitalize on the trend of collaborative consumption. Companies have the potential to profit from the sharing economy by connecting people and helping to make sharing more efficient (Matzler et al., 2015).

In this scenario, companies need to look at the key resources and processes of their business model considering the "fluidification" of the resources and who provides the key resource, either the businesses or the customers themselves (Kathan et al., 2016).

After an initial expectation that the resource fluidification could disrupt several established socio-technical and economic structures,

"if the sharing economy continues along this current pathway of corporate co-option it is highly unlikely to drive a transition to sustainability". (Martin, 2016, p.158-159).

The move of a big company such as General Motors, that has recently announced its intention to trial a service based on the Maven mobile App to enable car owners to rent their car when unused (Welch, 2018), is showing that the said pathway is not consolidated yet.

The sharing economy broad impact on individuals, companies, and society requests the introduction of policies to guarantee fair treatment for all parties and avoid inequality. Recently, in Europe, great attention has been put on privacy, personal data use, transparency and fair competition, by enforcing in 2018 the PSD2 and GDPR regulations mentioned in Section 3. These rules will help to increase the trustworthiness which is a key element for the success of the sharing economy. The creation of a sharing movement, suggested by (Schor, 2016), could be an instrument to revitalize and harness the less market oriented transformative power of the sharing economy for building social solidarity, democracy and sustainability.

In future, it is likely that the most successful companies will operate based on crowd solutions. After formulating new legal frameworks on sharing, our societies will follow massively this human-centric innovation approach, whose physical limits will be possibly overcome by the future combination of autonomous machines and human capabilities augmentation.

Acknowledgement. The contribution of Ioannis Mourgis to this work was carried out during his internship period in Telecom Italia S.p.A.

\section{References}

AirBnB (2018). Terms of Service. Accessed 24th April 2018.

url: http://www.airbnb.com/terms?locale $=$ en $\#$ sec13

Amazon Web Services (2016). Duolingo Case Study. Accessed 8th March 2018.

url: https://aws.amazon.com/it/solutions/case-studies/duolingo-case-study-dynamodb.

AT\&T (2014). The Innovation Pipeline. Accessed 8th March 2018.

url: http://about.att.com/content/dam/snrdocs/innovation_pipeline_052616.pdf.

Badger, E. (2015). Who millennials trust, and don't trust, is driving the new economy. Accessed 8th March 2018. www.washingtonpost.com/blogs/wonkblog/wp/2015/04/16/who-millennialstrust-and-dont-trust-is-driving-the-new-economy. 
Blind, K. (2012). Impact of Regulation on Innovation. NESTA Working Paper No. 12/02.

Botsman, R., \& Rogers, R. (2010). What's mine is yours: The rise of collaborative consumption. New York: Harper Collins.

Buczynski, B. (2011). Does Car Sharing Really Reduce Vehicle Ownership? Accessed 8th March 2018. www.shareable.net/blog/does-car-sharing-really-reduce-vehicle-ownership.

Candido dos Reis, F. J., Lynn, S., Ali, H.R. et al. (2015). Crowdsourcing the General Public for Large Scale Molecular Pathology Studies in Cancer. EBioMedicine.

Chen, M. K., Chevalier, J. A., Rossi, P. E., \& Oehlsen, E. (2017). The Value of Flexible Work: Evidence from Uber Drivers. NBER Working Paper No. 23296.

Chesbrough, H. (2011). Everything You Need to Know About Open Innovation. Accessed 8th March 2018.

url: www.forbes.com/sites/henrychesbrough/2011/03/21/everything-you-need-to-know-aboutopen-innovation.

Childs, M. (2013). The Power of Sharing: A Call to Action for Environmentalists. Accessed 8th March 2018. www.shareable.net/blog/the-power-of-sharing-a-call-to-action-for-environmentalists

De Beer, J., McCarthy, I. P., Soliman, A., \& Treen, E. (2017). Click here to agree: Managing intellectual property when crowdsourcing solutions. Business Horizons, 60(2).

Deloitte (2015). Facebook's global economic impact. Accessed 8th March 2018. url: www2.deloitte.com/content/dam/Deloitte/uk/Documents/technology-media-telecommunications/ deloitte-uk-global-economic-impact-of-facebook.pdf.

Edelman (2018). Trust Barometer Global Report. Accessed 8th March 2018. url: http://www.edelman.com/trust-barometer.

Einav, L., Farronato, C., \& J. Leviny, J. (2015). Peer-to-Peer Markets. NBER Working Paper No. 21496.

Elks, J. (2014). New Report Maps Size, Scope, Disruptive Potential of Sharing Economy. Accessed 8th March 2018.

url: www.sustainablebrands.com/news_and_views/next_economy/jennifer_elks/new_report_maps _size_scope_disruptive_potential_sharing_ec.

Fehrenbacher, K. (2010). How Web Sharing Sites Can Save The Planet. Accessed 8th March 2018.

url: https://gigaom.com/2010/09/06/how-web-sharing-sites-can-save-the-planet.

Fox, S. (2011). Medicine 2.0: Peer-to-peer healthcare. Accessed 8th March 2018.

url: www.pewinternet.org/2011/09/18/medicine-2-0-peer-to-peer-healthcare.

GDPR (2016). EU General Data Protection Regulation 2016/679. Accessed 8th March 2018. url: http://eur-lex.europa.eu/legal-content/EN/TXT/HTML/?uri=CELEX:32016R0679.

Gellman, R. (2015). Crowdsourcing, citizen science, and the law: legal issues affecting federal agencies. Accessed 8th March 2018.

url: https://wilsoncenter.org/sites/default/files/STIP_CS_Legal_FINAL.pdf. 
Gunther, M. (2014). Is Sharing Really Green? Accessed 8th March 2018.

url: http://ensia.com/voices/is-sharing-really-green.

Hamari, J., Sjoklint, M., \& Ukkonen, A. (2015). The Sharing Economy: Why People Participate in Collaborative Consumption. Journal of Association for Information Science and Technology.

Herbst, M. (2014). Let's get real: the 'sharing economy' won't solve our jobs crisis. Accessed 8th March 2018.

url: www.theguardian.com/commentisfree/2014/jan/07/sharing-economy-not-solution-to-jobscrisis.

Howard, A. (2015). How Digital Platforms Like LinkedIn, Uber And TaskRabbit Are Changing The On-Demand Economy. Accessed 8th March 2018.

url: www.huffingtonpost.com/entry/online-talent-platforms_us_55a03545e4b0b8145f72ccf6.

Hüetlin, T. (2013). Modern Mobility: CarSharing Gears Up in German Cities. Accessed 8th March 2018.

url: www.spiegel.de/international/zeitgeist/car-sharing-increasingly-popular-in-german-citiesa-913891.html.

Kathan, W., Matzler, K., \& Veider, V. (2016). The sharing economy: your business model's friend of foe? Business Horizons, 59(6).

Korosec, K. (2015). Another ride-sharing startup becomes a unicorn: BlaBlaCar valued at \$1.6 billion. Accessed 8th March 2018.

url: http://fortune.com/2015/09/16/blablacar-unicorn-list.

Kosoff, M. (2014). Business Insider Uber Has A Huge Group Of Lobbyists, And They're Helping Uber Achieve World Domination. Accessed 8th March 2018.

url: http://uk.businessinsider.com/uber-has-a-huge-group-of-lobbyists-to-help-it-take-over-theworld-2014-12.

Lieberstein, M., \& Tucker, A. (2012). Crowdsourcing and Intellectual Property Issues. Accessed 8th March 2018.

url: www.acc.com/legalresources/quickcounsel/caipi.cfm.

Lieberstein, M., Tucker, A. \& Yankovsky, A. K. (2012). Crowdsourcing: Understanding the Risks. Accessed 8th March 2018.

url: http://www.kilpatricktownsend.com/ /media/Files/articles/2012/MLieberstein\%20NYSBA.ashx.

Lombardi, P., \& Schwabe, F. (2017). Sharing Economy as a new business model for energy storage systems. Applied Energy, 188.

Martin, C. J. (2016). The sharing economy: A pathway to sustainability or a nightmarish form of neoliberal capitalism? Ecological Economics, 121.

Massolution (2015). 2015CF The Crowdfunding Industry Report. Accessed 8th March 2018. http://reports.crowdsourcing.org/index.php.

Matzler, K., Veider, V., \& Kathan, W. (2015). Adapting to the Sharing Economy. MIT Sloan Management Review, Winter 56(2). 
Parigi, P., \& Cook., K. (2015). Trust and relationships in the sharing economy. Accessed 8th March 2018. http://contexts.org/articles/on-the-sharing-economy/\#parigi.

Parsons, A. (2014). The sharing economy: a short introduction to its political evolution. Accessed 8th March 2016. http://www.sharing.org/information-centre/articles/sharing-economyshort-introduction- its-political-evolution.

Pew Research Center (2014). Millennials in Adulthood. Accessed 8th March 2018. url: http://www.pewsocialtrends.org/2014/03/07/millennials-in-adulthood.

Pick, F. (2012). Sustainability and the sharing economy. Accessed 8th March 2018.

url: http://www.francescapick.com/post/28845328387/sustainability-and-the-sharing-economy.

PriceWaterhouseCoopers (2014). The sharing economy: how will it disrupt your business? Megatrends: the collisions. Accessed 8th March.

url: 2018. http://pwc.blogs.com/files/sharing-economy-final_0814.pdf.

PSD2 (2015). EU Directive 2015/2366 on payment services in the internal market. Accessed 8th March 2018.

url: http://eur-lex.europa.eu/legal-content/EN/TXT/HTML/?uri=CELEX:32015L2366.

Ramirez, E. (2017). Duolingo Is Launching A Korean Course To Cash In On Asia's Booming Language Market. Accessed 8th March 2018.

url: www.forbes.com/sites/elaineramirez/2017/09/07/duolingo-korean-language-course-launch.

Ranchordas, L. (2015). Does sharing mean caring: regulating innovation in the sharing economy. The Minnesota Journal of Law, Science 83 Technology, 16(1).

Regner, M. (2014). Want to be the next AirBnB or Taskrabbit? Don't fall for these marketplace myths. Accessed 8th March 2018.

url: http://venturebeat.com/2014/12/14/want-to-be-the-next-AirBnB-or-taskrabbit-dont-fallfor- these-marketplace-myths.

Richter, F. (2014). The Rise of the Sharing Economy. Accessed 8th March 2018. url: http://www.statista.com/chart/2323/the-rise-of-the-sharing-economy.

Rick, T. (2013). A technology driven change - the collaborative economy. Accessed 8th March 2016.

url: www.torbenrick.eu/blog/strategy/the-collaborative-economy-a-technology-driven-change.

Rifkin, J. (2001). The Age of Access: The New Culture of Hypercapitalism, Where all of Life is a Paid-For Experience. New York: Tarcher / Putnam.

Schor, J. (2016). Debating the sharing economy. Journal of Self-Governance \& Management Economics, 4(3).

Scorpio, J. (2012). What's The Future Of The Sharing Economy? Accessed 8th March 2016. url: https://www.fastcompany.com/2679964/whats-the-future-of-the-sharing-economy.

Stähler, P. (2010). Open innovation: does it work? Accessed 8th March 2018. url: http://blog.business-model-innovation.com/2010/08/open-innovation-does-it-work.

Straifeld, D. (2014). AirBnB Listings Mostly Illegal, New York State Contends. Accessed 8th 
March 2018.

url: https://www.nytimes.com/2014/10/16/business/airbnb-listings-mostly-illegal-state-contends.html Sundararajan, A. (2016). The Sharing Economy. The End of Employment and the Rise of Crowd-Based Capitalism. Cambridge (MA): MIT Press.

Tanz, J. (2014). How AirBnB and Lyft Finally Got Americans to Trust Each Other. Accessed 31th March 2018.

url: http://www.wired.com/2014/04/trust-in-the-share-economy.

The Crowd Datacenter (2014). Mapping - The State of The Crowdfunding Nation. Accessed 8th March 2018.

url: https://www.scrt.scot/wp-content/uploads/2015/07/Crowdfunding-Centre-The_State_of_The _Crowdfunding_Nation_1st_HEADLINE_Edition.pdf.

Tordera, I. (2013). A Look at Italy's Enacted Regulations for Equity Crowdfunding. Accessed 8th March 2018.

url: http://news.crowdvalley.com/news/italy-enacts-regulations-for-equity-crowdfunding.

United Nations (2015). World Population Prospects. Key findings advance tables. Accessed 8th March 2018.

url: http://esa.un.org/unpd/wpp/Publications/Files/Key_Findings_WPP_2015.pdf.

Van den Dolder, T. (2014). Sharing Economy Companies Like Uber and AirBnB Make Lobbying a Priority. Accessed 8th March 2018.

url: http://www.americaninno.com/dc/sharing-economy-companies-like-uber- and-AirBnB-makelobbying-a-priority.

Vesselino, R., \& Greco, J. (2012). Duolingo Effectiveness Study. Accessed 8th March 2018.

url: http://static.duolingo.com/s3/DuolingoReport_Final.pdf

Welch, D. (2018). GM Plans to Launch Airbnb for Your Car. Accessed 8th March 2018.

url: www.bloomberg.com/news/articles/2018-03-13/gm-is-said-to-plan-airbnb-like-service- forsharing-your-wheels.

Wolfson, S. M., \& Lease, M. (2011). Look Before You Leap: Legal Pitfalls of Crowdsourcing. Proceedings of ASIST, 48, 1-10.

World Economic Forum (2013). Young Global Leaders - Circular Economy Innovation \& New Business Models Dialogue. Accessed 8th March 2018.

url: http://www3.weforum.org/docs/WEF_YGL_CircularEconomyInnovation_PositionPaper_2013.pdf

Zervas, G., Proserpio, D., \& Byers, J. W. (2015). The Rise of the Sharing Economy: Estimating the Impact of AirBnB on the Hotel Industry. Proceedings of the 16th ACM Conference on. Economics and Computation, 20-25. 


\section{Biographies}

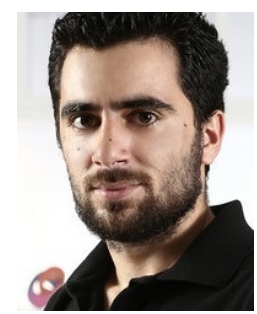

Ioannis Mourgis. Ioannis Mourgis (born in 1989) has studied future business technologies in Singularity University at NASA AMES Research Center. He holds a degree in Business Administration with a postgraduate diploma in Pedagogy from Athens University of Economics (AUEB). He also holds a 2nd level Master in the field of innovation and technology, by SantAnna University of advanced studies. His innovative ideas and research have been awarded by European Investment Bank, National Bank of Greece, Telecom Italia, Economic Review Journal, Athens University of Business and Economics, IST College and TEDxAcademy. As a visionary entrepreneur, Ioannis was the co-founder of Organery, HackAcademy and Nereus Maritime innovative startups. He also gave a public talk at Tedx, about the age of creativity. He is an urban activist, creator of Cyclists of Kalamata. Ioannis worked for several international companies in different sectors and countries, like Telecom Italia (Italy) and Peoplecert (Athens). Currently, he is working for Growthrocks (UK), the no1 growth hacking agency globally.

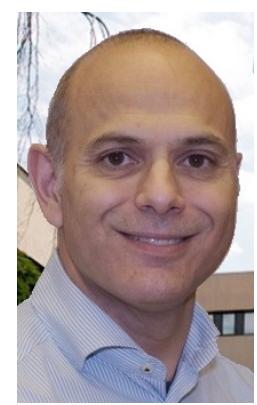

Gianluca Zaffiro. Gianluca Zaffiro joined Telecom Italia S.p.A.'s Research Labs (formerly CSELT) in 1994 and started working on fiber optics devices and related standardization activities. In 2000 he was devoted to Innovation and Strategic support of TIM marketing activities. Since 2006 he holds a position in the TIM Future Centre group as Project Manager. He successfully coordinated the Market Interaction WP of the FET FP6 PEACH Presence Research in Action project (2006-2009) and the Industry Landscape and Liaison WP of the FET FP7 UrbanIXD Urban Interaction Design coordination action (2013-2014). He has over 20 years of experience in Telecommunications and spent over 10 years in identifying future scenarios and trends in ICT. He holds an Electronic Engineering Degree from Politecnico of Torino, a Master Degree in Telecommunications and a PMPßcertification. He lectured on Smart Solutions and Smart Communities at the II Level Master of Scuola Superiore Sant'Anna of Pisa (2014-2015). He is author of several technical and dissemination papers on topics ranging from Optical Devices to Augmented and Virtual Reality, applied Neuroscience and Smart Cities. He contributes to the Telecom Italia Notiziario Tecnico (the Telecom Italia technical magazine).

\section{ISSN 2183-0606}

http://www.open-jim.org

http://creativecommons.org/licenses/by/3.0 